\title{
Perspectives in The Industrial Revolution 4.0 and A Glance Review of Impact to Supply Chain
}

\author{
Ade Paranata ${ }^{1 *}$, Chu-Chai Henry Chan ${ }^{2}$, Irwan Suriadi ${ }^{3}$ \\ ${ }^{1}$ Ph.D. Student, Department of Business Administration, Chaoyang University of Technology, Taiwan- \\ Department of Economics, University of Mataram, Indonesia \\ ${ }^{2}$ Department of Industrial Engineering and Management, Chaoyang University of Technology, Taiwan \\ ${ }^{3}$ Department of Economics, University of Mataram, Indonesia
}

*adeparanata@unram.ac.id

\begin{abstract}
Behind the magnitude of influence and benefits of ne digital Industry in various dimensions in most scientific literature, likewise, the co the contradictive arguments. This paper aims to figure out various theory statemen ither the pros or cons of the industrial revolution and also a glance of th impact the Industrial 4.0 to supply chain in an enterprise. A comparison of viewpoint bot the Neo-Classic group and Marxists on this paper is a difference with other references. That this paper using a literature review in which materials were from $m$ ny sources like Scopus, Science Direct, Sage Pub, etc. The element of dynamic process nd no we called by innovation is the Schumpeter theory. Marx's foresight will happen uccause the mechanical process on production will prune the class worker an mosive unemployment occurs.
\end{abstract}

Keywords: Industrial revolution 40 supply hain

\section{Introduction}

That fourth indust makes the magnificent change both qualitative and quantitative wide scales in life [1]. In 21 , Germany proposes industrial 4.0 thought on an economic policy that is based on advanced to nology [2]. Provided that can apply dual strategies in smart manufacturing in ustr al through keep in integration infor-mation and communication technology, Germany will - a leader in the world [3]. Now, many countries race to adopt a smart-tech in all sectors to the asiness of its citi-zens. People in rich countries can access easily the world in hand, for instance: transportation, shopping, education, etc. However, that is not easy for others which is inhabitant work in the labor-intensive industry, especially in the third world, because they will be replaced by robotic. According to [4] that there are many implications of the industrial revolution 4.0, even more, people can be connected to others, many organizations more simply, but the shift and disruption can bring to impending doom.

Further, the industrial revolution 4.0 has been devel-oping rapidly in most of the sectors. A few years ago, most governments and organizations around the world accepted the change of technology 4.0 [5]. That IR 4.0 has been being implemented in the construction industry has big challenges to ensure success in which social factor is one of the big barriers [6]. Moreover, in Brazil, with 27 sectors representing 2,225 firms, industry 4.0 gives a posi-tive and negative contribution to industrial performance [7]. 